\title{
Whistlestop tour
}

doi:10.1136/sti.2010.045625

This month, two papers deal with congenital syphilis, still a major cause of stillbirth and neonatal death in many parts of the world. Liu et al describe a cohort in which 554 pregnant women were followed up after treatment for syphilis, and report infection in $5.2 \%$ infants, including five whose mothers were treated before 28 weeks gestation. There was a correlation between maternal non-treponemal antibodies and the risk of congenital syphilis, which interacted with gestation at treatment (see page 292). ${ }^{1}$ In mobile, resource poor settings, IgM ABS may not be available, so Wu et al describe the sensitivity and specificity of several diagnostic algorithms in a paper that will be useful in a variety of settings (see page 280). ${ }^{2}$ The gap between populations still burdened by congenital syphilis and the developed world is highlighted by a case report by Read et al (see page 276) ${ }^{3}$ in which infectious syphilis unmasked HIV drug resistance, with important implications for transmissibility and HIV transmission. The authors conclude that patients need to realise that concurrent STIs will increase their HIV infectivitywhat about other transient infections, sexually acquired or otherwise.

Services around the world are grappling with new communication technologies, and their potential to improve or disrupt care. Richens et al (see page 310) ${ }^{4}$ report a randomised controlled trial of computerassisted interviewing in a UK sexual health clinic with equivocal results for the service. While computer-assisted interviewing increased disclosure of sexual risktaking, it was also associated with a reduction in HIV testing, and an increase in STI testing which did not result in increased diagnoses. HIV testing is likely to become an increasingly important outcome measure for services around the world, and the complexities of interpreting testing data are interestingly explored by White et al (see page 254). ${ }^{5}$ They compare cohort based estimates of recent HIV infection (using the 'STARHS' serological testing algorithm for recent HIV seroconversion), and demonstrate a potential bias in incidence estimates where these are applied to populations who choose their time of HIV testing.
While morbidity due to the classical venereal diseases remains well documented, 'nonspecific' genital infection remains poorly explained. When appointed to my first specialist training post, I was taken on a tour of the local research grandees, one of whom invited me to 'break my heart over the causes of nonspecific urethritis'. The heartbreak continues and Ondondo and colleagues (see page 271) ${ }^{6}$ have reported for our continuing puzzlement a positive relationship between Ureaplasma urealyticum and nongonococcal urethritis, yet a negative correlation with $U$ parvum. Similarly frustrating and complex has been the search for a unitary explanation of bacterial vaginosis. Brotman et al (see page $297)^{7}$ report rapid fluctuation in vaginal ecology, and an association between lubricant use and rectal sex with incident bacterial vaginosis - the authors highlight the need to harness molecular technologies to help our understanding of this complex condition.

Two different kinds of concurrency are explored this month. Beyrer et al (see page 323) report that a third of men who have sex with men (MSM) in Southern Africa acknowledge a regular or marital female partner, with over half reporting both male and female partners over the past 6 months. ${ }^{8}$ While bisexual concurrency was associated with higher rates of condom use, this is a common occurrence which needs to be usefully addressed both by HIV prevention programmes and by legislative structures. Another hidden population, this time reported from the Netherlands (see page 315), is 'swingers', heterosexual couples who swap partners or engage in group sex. ${ }^{9}$ Despite their median age of 43-in STI epidemiology, even 35 is over the hill-these patients had a Chlamydia prevalence of $10 \%$, a gonorrhoea prevalence of $4 \%$ and accounted for $55 \%$ of diagnoses over the age of 45 . Both these populations can easily be unrecognised in sexual health services, resulting in avoidable transmissions. What should we be doing to ensure, wherever we work, that we are recognising these important high risk groups?

Other topics explored this month include intravaginal practices, (see page 318) ${ }^{10}$ inadequate management of epididymo-
Jackie A Cassell, Editor

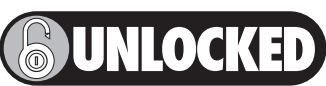

This paper is freely available online under the BMJ Journals unlocked scheme, see http://sti.bmj.com/site/ about/unlocked.xhtml

orchitis by urologists (see page 328), ${ }^{11}$ the association between genital warts and smoking (see page 258$)^{12}$ and self-medication (see page 285). ${ }^{13}$

\section{REFERENCES}

1. Liu J-B, Hong F-C, Pan P, et al. A risk model for congenital syphilis in infants born to mothers with syphilis treated in gestation: a prospective cohort study. Sex Transm Infect 2010;86:292-6.

2. Wu D-D, Hong F-C, Feng T-J, et al. Congenital syphilis: refining newborn evaluation and management in Shenzhen, southern China. Sex Transm Infect 2010;86:280-4.

3. Read PJ, Fox J. Infectious syphilis unmasking drug resistance in an individual with long-term virological suppression on antiretroviral therapy. Sex Transm Infect 2010;86:276-7.

4. Richens J, Copas A, Sadiq ST, et al. A randomised controlled trial of computer-assisted interviewing in sexual health clinics. Sex Transm Infect 2010;86:310-14.

5. White E, Goldbaum G, Goodreau G, et al. Interpopulation variation in HIV testing promptness may introduce bias in HIV incidence estimates using the serologic testing algorithm for recent HIV seroconversion. Sex Transm Infect 2010;86:254-57.

6. Ondondo RO, Whittington WLH, Astete SG, et al Differential association of ureaplasma species with non-gonococcal urethritis in heterosexual men. Sex Transm Infect 2010;86:271-5.

7. Brotman RM, Ravel J, Cone RA, et al. Rapid fluctuation of the vaginal microbiota measured by Gram stain analysis. Sex Transm Infect 2010;86:297-302.

8. Beyrer C, Trapence G, Motimedi F, et al. Bisexual concurrency, bisexual partnerships, and HIV among Southern African men who have sex with men. Sex Transm Infect 2010;86:323-7.

9. Dukers-Muijrers NHTM, Niekamp A-M, Brouwers $E E H G$, et al. Older and swinging; need to identify hidden and emerging risk groups at STI clinics. Sex Transm Infect 2010:86:315-17.

10. Gallo MF, Sharma A, Bukusi EA, et al. Intravagina practices among female sex workers in Kibera, Kenya. Sex Transm Infect 2010;86:318-22.

11. Phillips JT, Giebaly D, Gillham T, et al. Urological management of acute epididymo-orchitis in sexually active young men: too great a public health risk? Sex Transm Infect 2010;86:328.

12. Terning Hansen B, Hagerup-Jenssen M, Krüger Kjær $\mathbf{S}$, et al. Association between smoking and genital warts: Iongitudinal analysis. Sex Transm Infect 2010;86:258-62.

13. Gomez GB, Campos PE, Buendia C, et al. Studying complex interactions among determinants of healthcare-seeking behaviours: self-medication for sexually transmitted infection symptoms in female sex workers. Sex Transm Infect 2010;86:285-91. 